\title{
Enraizamento de miniestacas de Azadirachta indica A. Juss em substratos alternativos
}

\section{Erika Rayra Lima Nonato1*, Eder Ferreira Arriel1, Juliana Araújo Leite1, Mellina Nicácio da Luz1,} Lenita Goncalves da Costa ${ }^{1}$ e Izabel dos Santos Dias ${ }^{1}$

RESUMO: A Azadirachta indica A. Juss (Nim) é uma espécie nativa da Ásia e da África, possui boa distribuição em regiões de clima tropical e subtropical, como o Brasil. O presente estudo teve como objetivo avaliar a propagação clonal pela técnica de miniestaquia da Azadirachta indica A. Juss em função de substratos compostos por materiais alternativos disponíveis na região de Patos-PB. Avaliaram-se seis tratamentos em delineamento inteiramente casualizado, em parcelas constituídas de três miniestacas, com três repetições. $\mathrm{O}$ experimento foi realizado utilizando propágulos vegetativos de um minijardim clonal da espécie, localizado no Viveiro Florestal, na Universidade Federal de Campina Grande (UFCG), Campus Patos-PB. Coletaram-se no minijardim brotações, confeccionadas miniestacas e as mesmas foram plantadas em tubetes contendo os substratos a serem avaliados. Foram coletados dados de massa seca de raízes, da parte aérea, massa seca total e agregação do substrato às raízes. Submeteram-se os dados ao teste de normalidade de Lillierfors (D), apresentando distribuição normal. Realizou-se a análise de variância, teste $\mathrm{F}$ e a comparação das médias pelo teste de Scott-Knott. Em relação aos parâmetros coletados, os melhores resultados foram obtidos pelo substrato composto por $50 \%$ de casca de coco verde $+50 \%$ do coproduto resultante da extração de vermiculita.

Palavras-chave: miniestaquia, propagação clonal, impacto ambiental.

\section{Rooting of minicuttings of Azadirachta indica A. Juss on alternative substrates}

ABSTRACT: Azadirachta indica A. Juss (Nim) is a species native to Asia and Africa and has good distribution in tropical and subtropical regions such as Brazil. The present study aimed to evaluate the clonal propagation by Azadirachta indica A. Juss minicutting technique as a function of substrates composed of alternative materials available in the Patos-PB region. Six treatments were evaluated in a completely randomized design, in plots consisting of three minicuttings, with three replications. The experiment was carried out using vegetative propagules of a miniclonal hedge of the species, located in the Forest Nursery, Federal University of Campina Grande (UFCG), Campus Patos-PB. Sprouts were collected in minijardim, minicuttings were made and they were planted in tubes containing the substrates to be evaluated. Data were collected on dry mass of roots, shoot, total dry mass and substrate aggregation at roots. The data were submitted to the normality test of Lillierfors (D), presenting a normal distribution. The analysis of variance, F-test and the comparison of the means by the Scott-Knott test were performed. Regarding the parameters collected, the best results were obtained by the substrate composed of $50 \%$ of green coconut shell $+50 \%$ of the co-product resulting from vermiculite extraction.

Keywords: semiarid region, clonal propagation, environmental impact.

\section{INTRODUÇÃO}

As condições climáticas encontradas no Brasil possibilitam o desenvolvimento das espécies nativas, bem como favorecem no estabelecimento e no desenvolvimento de espécies exóticas na região, desde que o local a ser implantado forneça condições semelhantes à sua área de origem. Dessa maneira, a Azadirachta indica A. Juss (Nim) é uma espécie nativa da Ásia e da África, e possui boa distribuição em regiões de clima tropical e subtropical, como o Brasil. A árvore pertence à família Meliaceae, é de rápido crescimento e pode atingir até 25 metros de altura, em locais onde seus atributos são favoráveis ao seu crescimento (NEVES et al., 2003).

É possível utilizar partes da árvore para uma vasta diversidade de finalidades. Santos et al. (2017) constataram que há eficiência acaricida nos produtos a base de óleo de $\mathrm{Nim}$ (Organix ${ }^{\circledR}$ ) e o produto Pironim ${ }^{\circledR}$ para a praga do tomateiro $T$. evansi. $\mathrm{Na}$ região semiárida do nordeste brasileiro, a espécie possui destaque na arborização urbana, sendo encontrado predominantemente em diversas cidades da região, devido seu rápido crescimento aliado ao conforto térmico proporcionado pelas suas copas

Recebido em 05/07/2019, Aceito para publicação em 15/10/2019

${ }^{1}$ Universidade Federal de Campina Grande (UFCG)

*e-mail: kinhalima14@hotmail.com 
através do fornecimento de sombras (BRITO et al., 2012; NASCIMENTO, GUEDES, 2015; SILVA et al., 2018).

Pode ocorrer de algumas sementes da espécie possuírem comportamento recalcitrante, e assim perdem seu poder germinativo em um curto período de tempo. Em virtude deste fator limitante, as sementes devem ser plantadas pouco tempo após a sua colheita (MARTINEZ, 2002). Uma das alternativas para a propagação de espécies recalcitrantes se dá por meio da técnica de clonagem denominada miniestaquia através do estabelecimento de um minijardim clonal.

A miniestaquia pode ser entendida como uma derivação da estaquia habitual, consistindo na utilização de brotações provenientes de plantas propagadas pelo método de estaquia convencional ou de mudas de origem seminal (ALFENAS et al., 2004). Esta técnica é uma evolução da estaquia tradicional, trazendo alterações, principalmente, em relação ao controle nutricional e fitossanitário dos propágulos produzidos (STUEPP et al., 2018). Para executar o método da miniestaquia, é necessário selecionar e utilizar matrizes superiores para a formação do minijardim clonal, uma vez que este servirá de fonte de propágulos vegetativos e garantirá a produção de materiais com alta qualidade durante todo o ano.

Para a produção de mudas se tornar um método eficaz na propagação da espécie há a influência de uma diversidade de fatores como o tipo de recipiente a ser utilizado, bem como o substrato e a sua composição (BORSOI NETO, 2018). Dentre as propriedades que um bom substrato deve obter destacam-se a aeração adequada e boa capacidade de retenção de água, afetando diretamente no enraizamento em virtude de realizar a sustentação e permitir um bom suprimento de oxigênio e água para a base da estaca e para o seu desenvolvimento radicial.

Desta forma, o presente estudo teve como objetivo avaliar a propagação clonal pela técnica de miniestaquia da Azadirachta indica A. Juss (Nim) em função de substratos compostos por materiais alternativos disponíveis na região de Patos-PB.

\section{MATERIAL E MÉTODOS}

O experimento foi realizado utilizando propágulos vegetativos de um minijardim clonal da espécie, localizado no Viveiro Florestal da Unidade Acadêmica de Engenharia Florestal, na Universidade Federal de Campina Grande (UFCG), Campus Patos-PB.

Foram avaliados seis substratos: Vermiculita de granulometria média - T1; substrato comercial Bioplant ${ }^{\circledR}-\mathrm{T} 2$ (Ambos utilizados como testemunha); $2 / 3$ de terra de subsolo $+1 / 3$ de esterco animal - T3; pó da casca de coco verde (PC) - T4; coproduto resultante da extração de vermiculita (CV) - T5; e $50 \%$ de PC $+50 \%$ de CV - T6. Os materiais a serem avaliados foram acondicionados em tubetes de $280 \mathrm{~cm}^{3}$, alocados em bandeja com capacidade de suportar 54 tubetes.

Foram coletadas no minijardim clonal de Azadirachta indica A. Juss as brotações medindo 6,0 $\mathrm{cm}$ de comprimento para a confecção das miniestacas, com o auxílio de uma tesourinha de poda. A primeira etapa da pesquisa foi conduzida na casa de vegetação do viveiro florestal com telado que retém $50 \%$ da intensidade luminosa e irrigação automática, programados para ligar 20 vezes ao dia durante um minuto e em intervalos de 60 minutos, permanecendo neste ambiente por 68 dias. Na etapa seguinte as miniestacas foram transferidas para outra casa de vegetação com as mesmas propriedades do ambiente anterior, no entanto, a irrigação foi realizada manualmente, passando a ocorrer apenas uma vez ao dia até os 133 dias após o plantio, data do encerramento da pesquisa.

Para manter o estádio nutricional das miniestacas, foi adicionado um grama de macro e micronutrientes diluídos em $10 \mathrm{ml}$ de água com o auxílio de uma seringa, contendo a seguinte formulação: $13 \%$ de $\mathrm{N}$, $13 \%$ de $\mathrm{P}_{2} \mathrm{O}_{5}, 15 \%$ de $\mathrm{K}_{2} \mathrm{O}, 4 \%$ de $\mathrm{S}, 1 \%$ de $\mathrm{Ca}, 1 \%$ de $\mathrm{Mg}, 0,2 \%$ de $\mathrm{Fe}, 0,1 \%$ de $\mathrm{Zn}, 0,05 \%$ de $\mathrm{B}, 0,05 \%$ de $\mathrm{Cu} 0,005 \%$ de Co e $0,005 \%$ de Mo.

Os tratamentos foram avaliados em delineamento inteiramente casualizado, em parcelas constituídas de três miniestacas, com três repetições, totalizando 54 parcelas. Analisou-se o número de miniestacas que enraizaram, massa seca de raízes (MSR, em g), massa seca da parte aérea (MSPA, em g), massa seca total (MST) e a agregação do substrato às raízes, onde foram atribuídos notas entre 1 a 4 (1: pouca agregação do substrato às raízes; 2: agregação regular; 3: boa agregação e; 4: ótima agregação).

Os dados foram submetidos ao teste de normalidade de Lillierfors (D), análise de variância, teste F e as médias comparadas pelo teste de ScottKnott. Todas as análises foram realizadas por meio de software estatístico Assistat.

\section{RESULTADOS E DISCUSSÃO}

Em relação a variável agregação das raízes nos substratos foi observada um valor médio de 3,89 para a vermiculita; 3,78 (Bioplant $\AA)$; 2,67 (2/3 de terra de subsolo e 1/3 de esterco animal); 3,33 (pó da casca de coco verde - PC); 2,11 (coproduto resultante da extração de vermiculita - CV) e 3,78 $(50 \%$ de PC $+50 \%$ de CV) (Figura 1). É possível verificar que o substrato composto por $2 / 3$ de terra de subsolo e $1 / 3$ de esterco animal e o coproduto 
resultante da extração de vermiculita (CV) obtiveram valores médios inferiores, se comparado com os demais tratamentos, diferindo estatisticamente dos mesmos $(\mathrm{P}<0,05)$. Dessa maneira, constata-se que os substratos citados anteriormente garantem pouca ou nenhuma agregação dos mesmos às raízes.

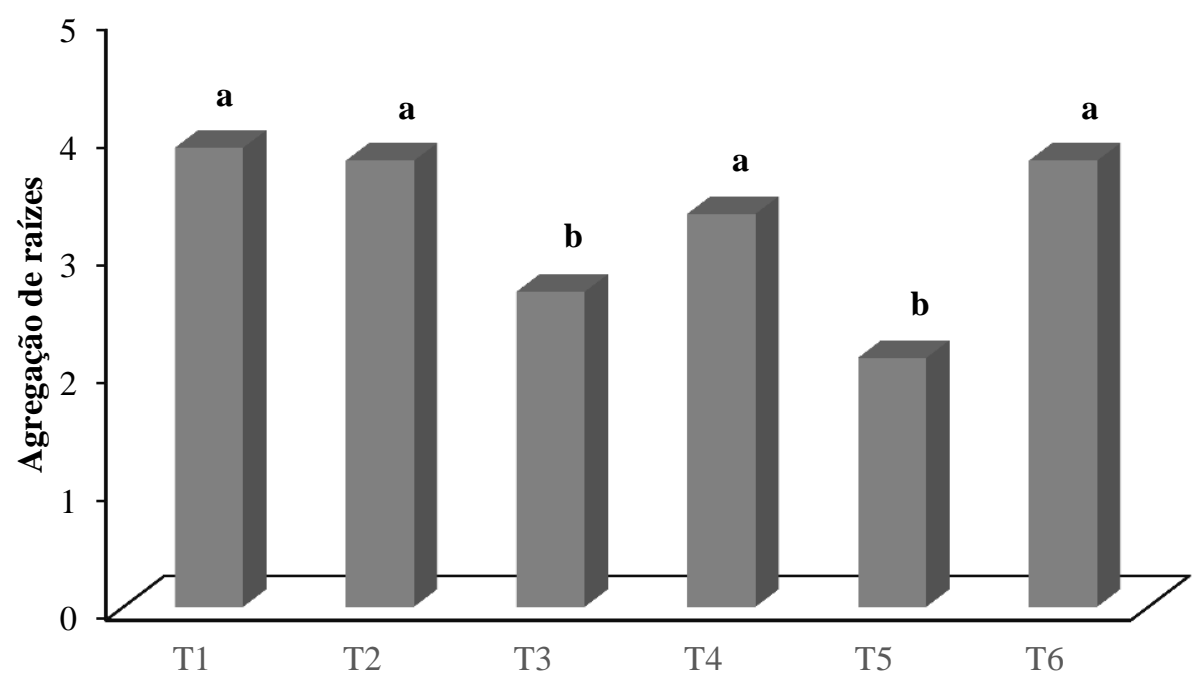

*Medias seguidas pela mesma letra não diferem entre si, pelo teste de Scott-Knott $(\mathrm{P}>0,05)$.

** T1: Vermiculita; T2: Substrato comercial Bioplant ${ }^{\circledR}$; T3: substrato composto por 2/3 de terra de subsolo e 1/3 de esterco animal; T4: pó da casca de coco verde (PC); T5: coproduto resultante da extração de vermiculita (CV) e T6: 50\% de PC + 50\% de CV

Figura 1- Médias da agregação das raízes nos substratos (Notas de 1 a 4) de miniestacas de Azadirachta indica A. Juss aos 133 dias após o plantio.

Entre os tratamentos avaliados a vermiculita, o Bioplant ${ }^{\circledR}$, o pó da casca do coco verde (PC) e o composto por $50 \%$ de PC $+50 \%$ de CV foram caracterizados por apresentar boa agregação pois receberam nota média superior a 3,0, todos estes obtendo a melhor classificação. Dentre estes, o tratamento testemunha vermiculita foi o que mais se aproximou a nota "4", considerada ótima em relação à capacidade de agregação. Além disso, é possível analisar que o coproduto resultante da extração da vermiculita (T5) não possuiu bons resultados isoladamente. No entanto, o tratamento $50 \%$ de PC $+50 \%$ de CV (T6) obteve resultados superiores, além dos já citados anteriormente. A partir destes resultados, verifica-se que, ao misturar o $\mathrm{PC}$ e o $\mathrm{CV}$, o material pó da casca do coco verde influenciou positivamente na capacidade de agregação do coproduto da vermiculita às raízes.

Avaliando a influência de diferentes substratos alternativos e estações do ano na qualidade de mudas clonais de Piptocarpha angustifólia, Stuepp et al. (2016) constataram que o substrato composto por $50 \%$ de fibra de coco $+50 \%$ de casca de arroz carbonizada e o composto por $30 \%$ de fibra de coco $+70 \%$ de casca de arroz carbonizada obtiveram os melhores resultados para agregação de raiz ao substrato.

Em relação as variáveis massa seca de raízes (MSR), massa seca da parte aérea (MSPA) e massa seca total (MST) o substrato testemunha vermiculita (T1) proporcionou o melhor resultado nos três atributos (Tabela 1), apresentando maiores taxas de biomassa.

O substrato testemunha Bioplant ${ }^{\circledR}$ também obteve média superior se comparado aos demais tratamentos. Este resultado positivo pode ser explicado pelo fato de se tratar de um substrato comercial, sendo produzido com uma formulação que auxilie no melhor desenvolvimento das miniestacas e de seus parâmetros, como a taxa de emissão radicular. O substrato composto por $50 \%$ de $\mathrm{PC}+50 \%$ de CV obteve resultados positivos de massa seca, se aproximando aos resultados apresentados pelos tratamentos testemunhas, não diferindo significativamente quanto à MSPA e a MST.

Resultados inferiores foram encontrados por Cerqueira et al. (2017) estudando diferentes níveis de adubação na produção de mudas clonais de Eucalipto. Os autores verificaram que, aos 120 dias após o plantio das miniestacas, os valores médios para a MSR, em gramas, foram de 0,74; 0,99 e 0,92 para os clones AEC 144, GG 100 e VM 01, respectivamente. Dessa forma, verifica-se a possibilidade de haver influência direta e positiva da aplicação de adubo na emissão e no desenvolvimento radicular das miniestacas. 
Tabela 1. Valores médios de massa seca de raízes (MSR), massa seca da parte aérea (MSPA) e massa seca total (MST), em gramas.

\begin{tabular}{crrr}
\hline Tratamentos & MSR $(\mathrm{g})$ & MSPA $(\mathrm{g})$ & MST (g) \\
\hline T1 & $1,95 \mathrm{a}$ & $2,33 \mathrm{a}$ & $4,28 \mathrm{a}$ \\
T2 & $1,54 \mathrm{~b}$ & $2,36 \mathrm{a}$ & $3,9 \mathrm{a}$ \\
T3 & $1,08 \mathrm{c}$ & $1,39 \mathrm{~b}$ & $2,47 \mathrm{~b}$ \\
T4 & $1,12 \mathrm{c}$ & $1,2 \mathrm{~b}$ & $2,32 \mathrm{~b}$ \\
T5 & $1,01 \mathrm{c}$ & $1,4 \mathrm{~b}$ & $2,41 \mathrm{~b}$ \\
T6 & $1,43 \mathrm{~b}$ & $2,17 \mathrm{a}$ & $3,6 \mathrm{a}$ \\
\hline
\end{tabular}

* T1: Vermiculita; T2: Bioplant ${ }^{\circledR}$; T3: substrato composto por 2/3 de terra de subsolo e 1/3 de esterco animal; T4: pó da casca de coco verde (PC); T5: coproduto resultante da extração de vermiculita (CV); T6: 50\% de PC + 50\% de CV.

** Médias seguidas pela mesma letra, na coluna, não diferem entre si, pelo teste de Scott-Knott $(\mathrm{P}>0,05)$.

Ao avaliar a eficiência do enraizamento de miniestacas de clones de Eucalyptus grandis $\mathrm{x}$ Eucalyptus urophylla, Queiroz (2013) aponta que os melhores resultados de enraizamento se dão em tratamentos que apresentaram miniestacas mais vigorosas e sadias, o qual é evidenciado pelos elevados índices de agregação de raízes. Dessa forma, entende-se que os baixos valores médios de enraizamento no substrato composto por $2 / 3$ de terra de subsolo e 1/3 de esterco animal e o coproduto resultante da extração de vermiculita $(\mathrm{CV})$ podem estar relacionados aos baixos teores de agregação de raízes aos substratos.

Finalmente, salientamos a necessidade de avaliar as miniestacas da espécie e demais atributos por um maior período de tempo, visando obter maior consistência nos dados obtidos. Além disso, é relevante considerar a proposta sugerida por Luz (2018) para a clonagem da espécie Myracrodruon urundeuva Allemão, onde a autora ressalta a necessidade de avaliar outros componentes para a formação de substratos, bem como analisar os compostos estudados na pesquisa em diferentes proporções como o pó da casca de coco verde e o coproduto resultante da extração de vermiculita. O uso desses materiais são alternativas favoráveis pois auxiliam a reduzir os impactos ambientais provocados pelo descarte e acúmulo desses materiais no meio ambiente (NOBERTO, 2013), além do fato de serem de fácil aquisição devido à alta disponibilidade e o baixo custo na região do presente estudo.

\section{CONCLUSÕES}

O substrato com resultados satisfatórios, ao considerar a agregação de raízes e produção de biomassa, foi obtido pelo substrato composto por $50 \%$ de casca de coco verde $+50 \%$ do coproduto resultante da extração de vermiculita (T6).

\section{REFERÊNCIAS}

ALFENAS, A. C.; ZAUZA, E. A. V.; MAFIA, R. G.; ASSIS, T. F. Clonagem e Doenças do Eucalipto. Viçosa-MG: Editora UFV. 442p. 2004.

BORSOI NETO, A. C.; SEIF, M. E.; COLOMBO, J. N.; KRAUSE, M. R.; DALEPRANE, F. B.; LUCAS JUNIOR, H. V. Produção de mudas de maxixe em substratos alternativos. 2018. In: VI CONGRESSO LATINO-AMERICANO DE AGROECOLOGIA. 2017. Brasília-DF.

BRITO, D. R. S.; RAABE, J.; SOUSA, W. C.; MELO, R. R.; PEDROSA, T. D. Diagnóstico da arborização das praças públicas no município de Bom Jesus, Piauí. Revista Scientia Plena, v. 8, n. 4, 2012.

CERQUEIRA, P. H. A.; AZEVEDO, G. B.; SOUZA, A. M.; AZEVEDO, G. T. O. S. Adubação residual na produção de mudas clonais de eucalipto. Colombo: Pesquisa Florestal Brasileira, v. 37, n. 90, 119-129p. 2017.

LUZ, M. N. Miniestaquia seminal em Myracrodruon urundeuva Allemão com o uso de substratos alternativos. 2018. 44f. Monografia (Graduação em Engenharia Florestal) - Universidade Federal de Campina Grande, Paraíba.

MARTINEZ, S. S. O Nim - Azadirachta indica: natureza, usos múltiplos, produção. Londrina: IAPAR. 2002. 142 p.

NASCIMENTO, J. F.; GUEDES, J. A. Arborização urbana do espaço público de Major Sales. Caderno de Estudos Geoambientais - CADEGEO. v. 06, n. 01, p.17-31, 6p. 2015.

NEVES, B. P.; OLIVEIRA, I. P.; NOGUEIRA, J. C. M. Cultivo e Utilização do Nim Indiano. EMBRAPA Circular Térnica, 62. Santo Antônio de Goiás-GO. 12p. 2003.

NOBERTO, M N. Efeito dos substratos rejeito de vermiculita, fibra e pó de coco verde no enraizamento de alporques de faveleira (Cnidoscolus quercifolius 
Pohl). 2013. 64f. Dissertação (Mestrado em Ciências Florestais) - Universidade Federal de Campina Grande, Paraíba.

QUEIROZ, D. Eficiência do substrato no enraizamento de miniestacas de clones de Eucalyptus grandis $\mathbf{x}$ Eucalyptus urophylla. Trabalho de título em Gestão Florestal no curso de Pós-graduação de Gestão Florestal. UFPR. 17p. 2013.

SANTOS, M. D.; MACIEL, A. G. S.; TRINDADE, R. C. P.; SILVA, E. S.; DUARTE, A. G. eficiência do óleo de nim e do extrato pironim sobre o ácaro vermelho do tomateiro Tetranychus evansi BAKER \& PRITCHARD (ACARI: TETRANYCHIDAE). Rio Largo: Revista Ciência Agrícola, v. 15, n. 2, 53-59p. 2017.

SILVA, L. S.; OLIVEIRA, Y. R.; SILVA, P. H.; PIMENTEL, R. M. M.; ABREU, M. C. Inventário das plantas arbustivo-arbóreas utilizadas na arborização urbana em praças públicas. Journal of Environmental Analysis and Progress, v. 3, n. 2, 241-249p. 2018.

STUEPP, C. A.; WENDLING, I.; KOEHLER, H. S.; ZUFFELLATO-RIBAS, K. C. Quality of clonal plants of Piptocarpha angustifolia in diferente renewable substrates and seasons of the year. Brasília-DF: Pesquisa Agropecuária Brasileira, v. 51, n. 11, 1821-1829p. 2016.

STUEPP, C. A.; WENDLING, I.; XAVIER, A.; ZUFFELLATO-RIBAS, K. C. Vegetative propagation anda application of clonal forestry in Brazilian native tree species. Brasília-DF: Pesquisa Agropecuária Brasileira, v. 53, n. 9, 985-1002p. 2018. 